\title{
Analisa Kapasitas Dan Kinerja Persimpangan Tak Bersinyal R.A Kartini
}

\author{
Rocky Huliselan ${ }^{1}$, Muhammad Rusmin ${ }^{2}$ \\ 1,2 Progam Studi Teknik Sipil, Fakultas Teknik, Universitas Muhammadiyah Sorong
}

\begin{abstract}
Abstrak
Persimpangan adalah simpul dalam jaringan transportasi dimana dua atau lebih ruas jalan bertemu, disini arus lalu lintas sering mengalami konflik. Untuk mengendalikan konflik ini ditetapkan aturan lalu lintas untuk menetapkan siapa yang mempunyai hak terlebih dahulu untuk menggunakan persimpangan. Dengan selalu bertambahnya pengguna jalan, terutama pada jam - jam (jam puncak) tertentu sehingga menuntut adanya peningkatan kualitas dan kuantitas suatu jalan. Tujuan penelitian ini adalah untuk mengetahui kapasistas dan kinerja dari persimpangan tak bersinyal jalan R.A. Kartini Kota Sorong dengan menggunakan Metode Manual Kapasitas Jalan Indonesian (MKJI) 1997 dan program Excel 2014 untuk mengolah data lalulintas. Dalam studi di simpang tak bersinyal akan diamati mengenai kinerja, perilaku pengemudi mengambil celah diantara kendaraan dan kapasitas potensial pergerakan kendaraan di jalan minor dan jalan utama untuk dapat memasuki simpang. Dari hasil analisa kapasitas dan kinerja simpang tak bersinyal R.A. Kartini berdasarkan MKJI 1997. Besar Kapasitas pada simpang tak bersinyal R.A Kartini pada periode puncak pagi (07.00-08.00) sebesar 3,310.89 smp/jam, pada puncak siang (pukul 13.00-14.00) sebesar 3,190.65 smp/jam, dan pada puncak sore (pukul 17.00-18.00) kapasitas sebesar 3,333.62 smp/jam. Tingkat kinerja simpang tak bersinyal pada jalan R.A. Kartini pada saat jam sibuk dalam keadaan tidak jenuh karena mempunyai nilai derajat kejenuhan 0,3 - 0,46 kurang dari yang di syaratkan MKJI 1997 yaitu 0,75.
\end{abstract}

Kata Kunci : Derajat Kejenuhan, Kapasitas, Kinerja Persimpangan, R.A. Kartini.

\section{PENDAHULUAN}

Persimpangan adalah simpul dalam jaringan transportasi dimana dua atau lebih ruas jalan bertemu, disini arus lalu lintas sering mengalami konflik. Untuk mengendalikan konflik ini ditetapkan aturan lalu lintas untuk menetapkan siapa yang mempunyai hak terlebih dahulu untuk menggunakan persimpangan. Dengan selalu bertambahnya pengguna jalan, terutama pada jam - jam (jam puncak) tertentu sehingga menuntut adanya peningkatan kualitas dan kuantitas suatu jalan.

Persimpangan pada jalan R.A. Kartini tersebut terletak di kawasan pendidikan dan perbelanjaan maka aktifitas disamping jalan seperti pengangkutan barang-barang, penyeberangan orang yang tidak teratur, dan aktifitas naik-turun penumpang dari angkutan umum, serta kendaraan yang berhenti menyebabkan kemacetan sehingga membuat antrian kendaraan yang sangat panjang, bahkan bisa mengurangi waktu tempuh perjalanan. Hal ini menyebabkan kinerja simpang yang tidak optimal dalam melayani pengguna simpang.

\section{METODOLOGI}

Penelitian ini dilakukan di simpang tak bersinyal R.A. Kartini kota Sorong. Berikut ini adalah letak lokasi penelitian.

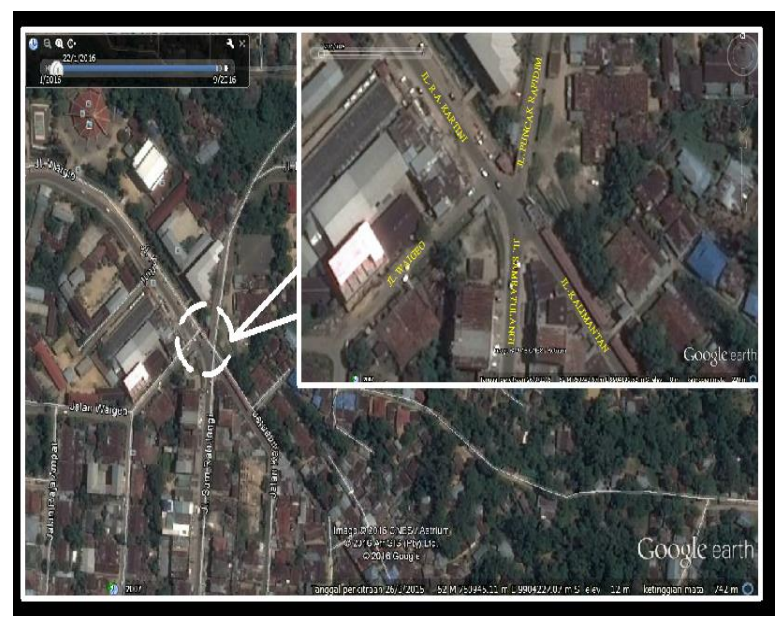

Gambar 1. Peta Lokasi Penelitian Simpang Tak Bersinyal jalan R.A Kartini

Data yang digunakan dalam penelitian ini bersumber dari data primer, data sekunder, data volume kendaraan, data primer dan data volume 
kendaraan yaitu data yang diperoleh dengan melakukan langsung pengumpulan di lokasi yang menjadi objek penelitian. Sedangkan data sekunder adalah data yang digunakan untuk menganalisis kinerja simpang, data ini diperoleh dari ketetapan yang sudah ada yaitu MKJI dan Badan Pusat Statistik (BPS). Data sekunder yang diperlukan adalah jumlah penduduk kota sorong.

Flowchart penelitian digunakan sebagai dasar pelaksanaan penelitian serta untuk lebih mempermudah dalam penelitian tersebut. Flowchart penelitian dapat dilihat pada gambar dibawah ini :

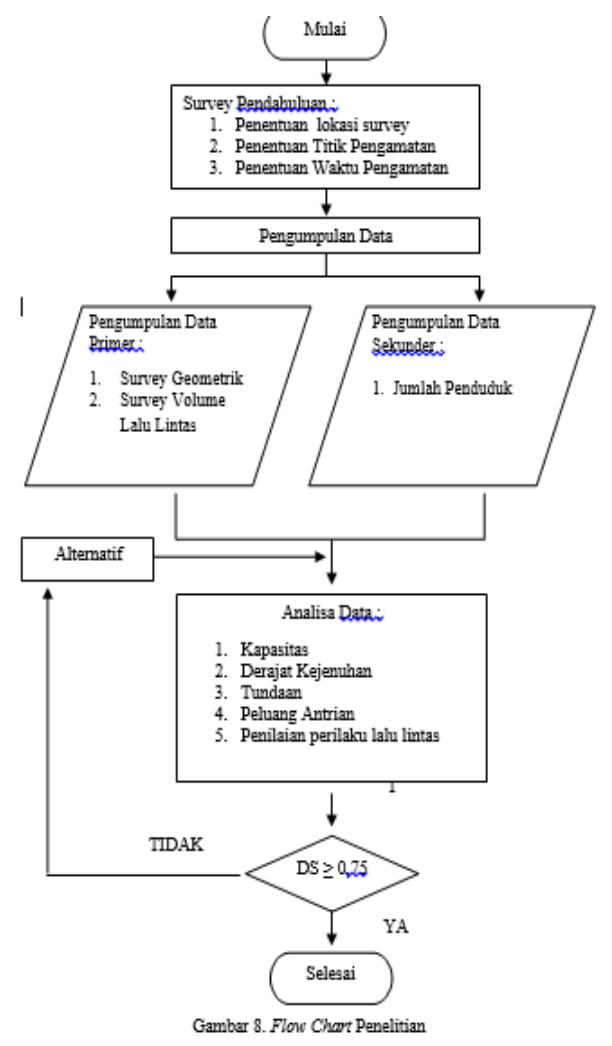

Gambar 2. Flowchart Penelitian

\section{HASIL DAN PEMBAHASAN 3.1 Kondisi Geometrik}

Simpang Lima Tak Bersinyal R.A. Kartini menghubungkan jalan Utama yaitu Jalan Samratulangi dan jalan R.A. Kartini ,jalan puncak cendrawasih dibagian utara, jalan waigeo dibagian selatan, dan jalan Kalimantan dibagian timur. Berikut kondisi geometrik simpang Lima Tak Bersinyal R.A. Kartini.

Hasil pengukuran geometrik jalan diperoleh dari pengukuran langsung dilapangan. Pada persimpangan ini, jumlah pendekat sebanyak 5 pendekat dengan lebar eksisting pendekat simpang yang bervariasi. Jalan Samratulagi dengan lebar perkerasan 9 meter dan dengan bahu jalan lebar 1,5 m. jalan R.A Kartini lebar perkerasan $8 \mathrm{~m}$ dengan bahu jalan lebar 1,5 $\mathrm{m}$. sedangkan jalan Minor jalan Kalimantan mempunyai lebar 4,5 $\mathrm{m}$, jalan puncak cendrawasih lebar pendekat $6 \mathrm{~m}$, jalan waigeo mempunyai lebar $6 \mathrm{~m}$.

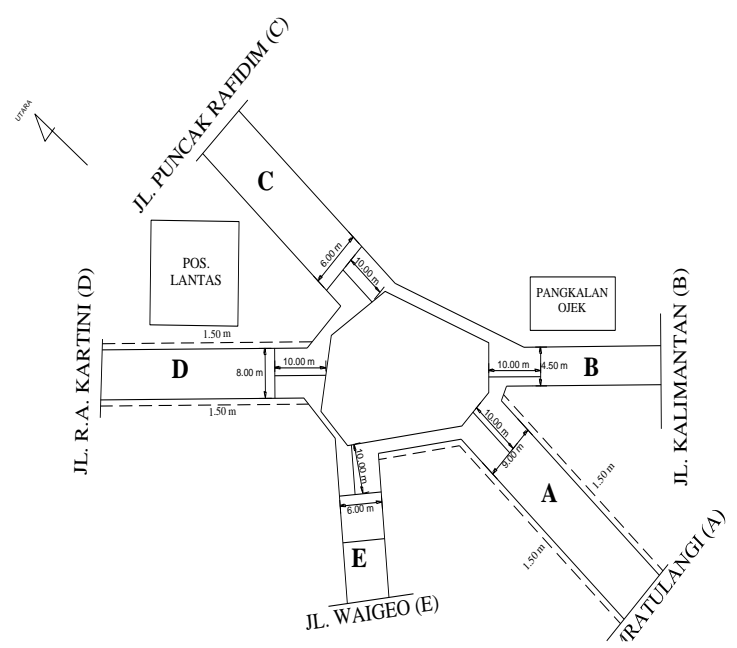

Gambar 3. Denah dan Situasi Geometrik Simpang

\subsection{Formulir USIG-I}

Geometrik, dan Arus Lalulintas. Pada Tabel di bawah ini data arus lalu lintas rata-rata pada periode puncak pagi, siang, dan sore pada semua pendekat, diperlihatkan tiap jenis kendaraan $\mathrm{LV}, \mathrm{HV}$, dan MC dibagi sesuai dengan pendekat masing-masing berdasarkan proporsi yang telah didapatkan sebelumnya. Tiap jenis kendaraan ini (LV,HV,MC) yang masih dalam satuan kendaraan per jam, kemudian dikonversikan ke dalam smp/jam dilakukan dengan mengalikan emp yang tercatat pada formulir $(\mathrm{LV}=1,0$; $\mathrm{HV}=1,3$; $\mathrm{MC}=0,5)$. Perhitungan Rasio belok, yaitu belok kiri dan Belok Kanan sesuai masingmasing pendekat. Perhitungan Rasio Jl. Minor / total Jl.Utama dan Minor juga diikut sertakan.

Tabel 9. Formulir USIG-I Periode puncak pagi

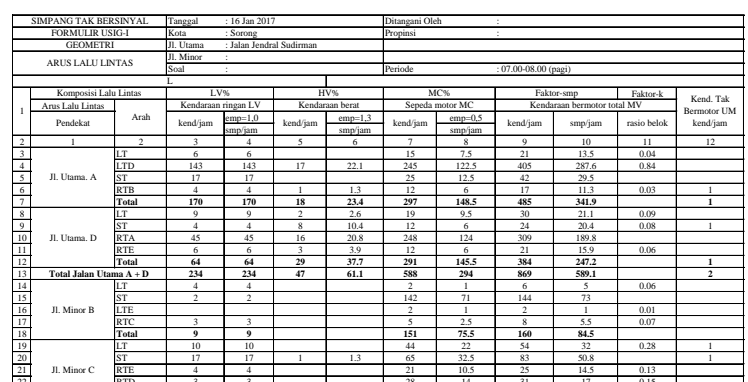


Tabel 10. Formulir USIG-I Periode puncak siang

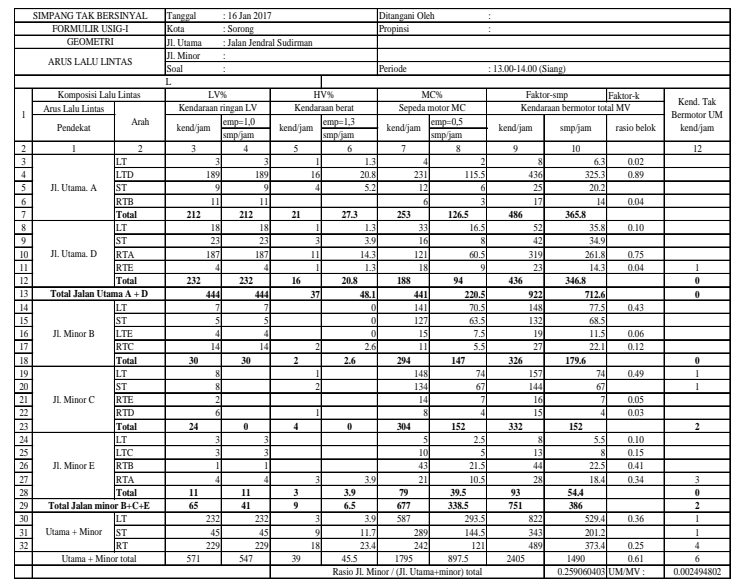

Tabel 12. Formulir USIG-I Periode puncak sore

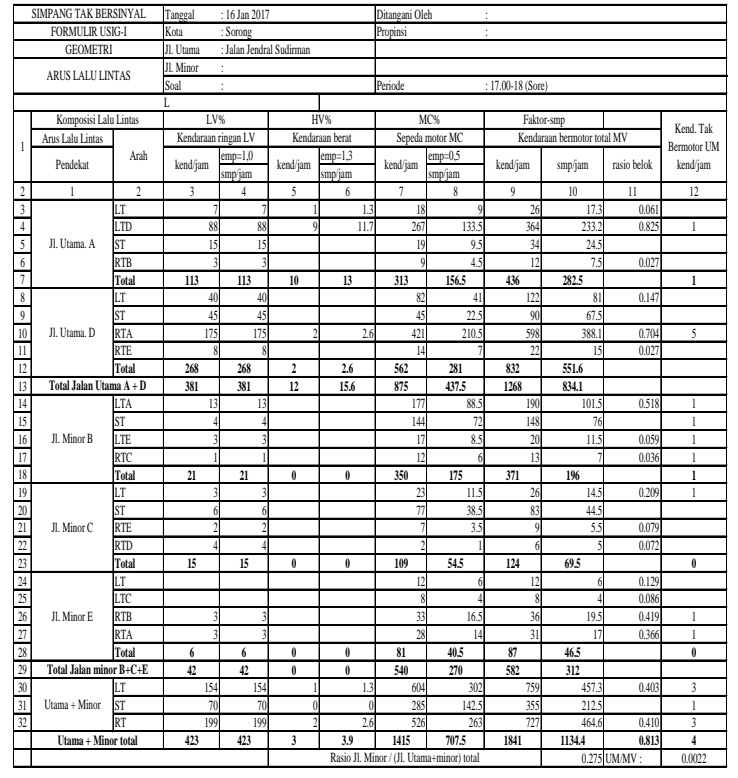

\subsection{Kapasitas}

\section{Lebar pendekatan}

Faktor Penyesuaian Lebar, Fw Lebar pendekat setiap simpang pada jalan utama dan jalan minor dihitung dengan persamaan berikut : $\mathrm{WAC}=(\mathrm{WA}+\mathrm{WC}) / 2 ; \mathrm{WBD}=(\mathrm{WB}+\mathrm{WD}) / 2$
$\mathrm{WABCD}=\frac{(4,5+2,25+3+4+3)}{4}=3,44 \mathrm{~m}$

Sedangkan lebar rata-rata pendekat WI dapat dihitung dengan persamaan sebagai berikut :WI $=(\mathrm{WA}+\mathrm{Wc}+\mathrm{WB}+\mathrm{WD}) /$ jumlah lengan simpang

$$
\mathrm{WI}=\frac{(4,5+2,25+3+4+3)}{4}=3,35 \mathrm{~m}
$$

\section{Kapasitas Dasar}

Kapasitas dasar Co didapat dari tabel kapasitas jalan kota Co $(\mathrm{smp} / \mathrm{jam})=2900$ berdasarkan table dibawah ini

\section{Faktor penyesuaian lebar pendekat}

Faktor penyesuaian lebar pendekat dihitung

Tabel 10. Kapasitas dasar jalan

\begin{tabular}{|c|c|c|}
\hline Tipe Jalan & $\begin{array}{c}\text { Kapasitas Dasar } \\
\text { (smp/jam) }\end{array}$ & catatan \\
\hline $\begin{array}{c}\text { Empat - lajur terbagi atau } \\
\text { satu-arah }\end{array}$ & 1650 & Per lajur \\
\hline $\begin{array}{c}\text { Empat - lajur tak terbagi } \\
\text { Dua - lajur tak terbagi }\end{array}$ & 1500 & Per lajur \\
\hline
\end{tabular}

Sumber: MKJI 1997

dengan persamaan :

$\mathrm{FW}=0,70+0,0866 \times \mathrm{WI}$

$\mathrm{FW}=0,70+0,0866 \times 3,35=0,9901$

Keterangan :

$\mathrm{WI}=$ Lebar rata - rata semua Pendekat 3,35m

\section{Faktor penyesuaian median jalan utama}

Pertimbangan teknik lalu-lintas diperlukan untuk menentukan faktor median. Median disebut lebar jika kendaraan ringan standar dapat berlindung pada daerah median tanpa mengganggu arus berangkat pada jalan utama. Hal ini mungkin terjadi jika lebar median $3 \mathrm{~m}$ atau lebih. Pada beberapa keadaan, misalnya jika pendekat jalan utama lebar, hal ini mungkin terjadi jika median lebih sempit.

Karena dijalan utama tidak terdapat median maka faktor penyesuaian median digunakan adalah 1,00, sesuai pada tabel 4 faktor penyesuaian median jalan utama.

\section{Faktor penyesuaian ukuran kota}

Menurut Badan Pusat Statistik (BPS) jumlah penduduk kota sorong pada tahun 2016 adalah 225,588 jiwa. Dari faktor penyesuaian ukuran kota kecil dengan jumlah penduduk 0,1 - 0,5 juta jiwa berarti faktor penyesuaian ukuran kota yang digunakan adalah 0,88 . 
6. Faktor penyesuaian Tipe Lingkungan Jalan Hambatan Samping dan Kendaraan Tak Bermotor

Faktor penyesuaian tipe lingkungan jalan, hambatan samping dan kendaraan tak bermotor, FRSU dihitung dengan menggunakan Tabel 6. Variabel masukan adalah tipe lingkungan jalan RE, kelas hambatan samping SF dan rasio kendaraan tak bermotor UM/MV. Karena hambatan samping tidak diketahui, maka dapat dianggap sebagai tinggi agar tidak menilai kapasitas terlalu besar dengan nilai 0,93

\section{Faktor penyesuaian belok-kiri}

Faktor penyesuaian belok-kiri ditentukan dengan persamaan :

FLT $=0,84+1,61 \times$ PLT

Faktor penyesuaian belok-kiri untuk periode puncak pagi :

$\mathrm{FLT}=0,84+1,61 \times 0,36=1,42$

Faktor penyesuaian belok-kiri untuk periode puncak siang :

FLT $=0,84+1,61 \times 0,35=1,41$

Faktor penyesuaian belok-kiri untuk periode puncak sore :

$\mathrm{FLT}=0,84+1,61 \times 0,40=1,48$

Keterangan :

PLT $=$ Rasio Kendaraan belok Kiri Didapat dari Formulir USIG -I puncak pagi,siang, sore baris 31 , kolom 11

\section{Faktor penyesuaian belok kanan}

Faktor penyesuaian belok kanan yang diberikan adalah rentang dasar empiris dari manual. Untuk simpang 5-lengan FRT $=1.00$

\section{Faktor penyesuaian rasio jalan minor}

Faktor penyesuaian arus jalan minor dapat dihitung dengan persamaan : $\mathrm{FMI}=1,19 \times$ $\mathrm{PMI}^{2}-1,19 \times \mathrm{PMI}+1,19$

Faktor penyesuaian rasio jalan minor untuk periode puncak pagi :

$\mathrm{FMI}=1,19 \times 0,21^{2}-1,19 \times 0,21+1,19=0,991$

Faktor penyesuaian rasio jalan minor untuk periode puncak siang :

$\mathrm{FMI}=1,19 \times 0,26^{2}-1,19 \times 0,26+1,19=0,961$

Faktor penyesuaian rasio jalan minor untuk periode puncak sore :
$\mathrm{FMI}=1,19 \times 0,27^{2}-1,19 \times 0,27+1,19=0,952$

Keterangan :

PMI = Rasio Arus Jalan Minor Total dapat dilihat pada Formulir USIG-1 pagi, saing, sore baris 35 , kolom 10

\section{Kapasitas}

Kapasitas dihitung dengan menggunakan persamaan 1 sebagai berikut :

$\mathrm{C}=$ Co $\mathrm{x}$ FW $\mathrm{x}$ FM $\mathrm{x}$ FCS $\mathrm{x}$ FRSU $\mathrm{x}$ FLT $\mathrm{x}$ FRT x FMI

Perhitungan kapasitas untuk periode pagi :

$\mathrm{C}=2900 \times 0,99 \times 1 \times 0,88 \times 0,93 \times 1,420 \times 1 \times$ $0,991=3,310.89$ (smp/jam)

Perhitungan kapasitas untuk periode siang :

$\mathrm{C}=2900 \times 0,99 \times 1 \times 0,88 \times 0,93 \times 1,412 \times 1 \times$ $0,961=3.190,65$ (smp/jam)

Perhitungan kapasitas untuk periode sore :

$\mathrm{C}=2900 \times 0,99 \times 1 \times 0,88 \times 0,93 \times 1,489 \times 1 \times$ $0,953=3,333.62(\mathrm{smp} / \mathrm{jam})$

Keterangan :

$\mathrm{C}=$ Kapasitas

Co = Kapasitas Dasar 2900 (smp/jam)

$\mathrm{Fw}=$ Faktor penyesuaian lebar masuk 0,99

$\mathrm{Fm}=$ Faktor Penyesuaian median alan utama 1

Fcs $=$ Faktor Penyesuaian Ukuran Kota 0,88

$\mathrm{FRSU}=$ faktor penyesuaian tipe lingkungan jalan, hambatan samping dan kendaraan tak bermotor 0,93

FLT $=$ Faktor penyesuaian belok kiri 1,420

FRT $=$ Faktor penyesuaian belok kanan 1

FMI $=$ Faktor penyesuaian rasio arus jalan minor 0,991

\subsection{Kinerja Lalu Lintas}

\section{Derajat Kejenuhan}

Derajat kejenuhan (DS) merupakan rasio arus lalu lintas (smp/jam) terhadapkapasitas (smp/jam), dengan menggunakan persamaan 7 sebagai berikut :

DS = Qtot $/ \mathrm{C}$

a. Perhitungan derajat kejenuhan untuk periode pagi :

$\mathrm{DS}=1.018,7 / 3.310,89=0,30(\mathrm{smp} / \mathrm{jam})$

Keterangan :

Qtot $=$ Arus total sesungghunya smp/jam, (dapat dilihat pada formulir USIG-I periode puncak pagi, siang, sore baris 34 , kolom 10) $\mathrm{C}=$ kapasitas 
b. Perhitungan derajat kejenuhan untuk periode siang :

$\mathrm{DS}=1,490 / 3,190.65=0,46(\mathrm{smp} / \mathrm{jam})$

c. Perhitungan derajat kejenuhan untuk periode sore :

$\mathrm{DS}=1.134,4 / 3.333,62=0,34(\mathrm{smp} / \mathrm{jam})$

Derajat kejenuhan di lapangan DS $=0,30-$ 0,46 tidak melebihi dari yang di syaratkan MKJI $\leq 0.75$, jadi DS di simpang R.A Karitni tersebut menunjukkan bahwa simpang tak bersinyal di R.A Kartini masih dalam kondisi baik.

\section{Tundaan}

1. Tundaan lalu-lintas simpang (DTi)

Tundaan lalu-lintas simpang DTi (detik/smp) adalah tundaan arus lalu-lintas untuk seluruh kendaraan bermotor yang masuk simpang. Tundaan DTi ditentukan dari hubungan empiris antara tundaan DTi dan derajat kejenuhan DS.

a. Untuk DS $\leq 0,6$ :

DT $=2+8,2078 \times$ DS $-(1-D S) \times 2$

Perhitungan tundaan lalu lintas simpang untuk periode pagi :

$\mathrm{DT}=2+[(8,2078 \times 0,307)]-[(1-$ $0,307) \times 2]=3,140($ detik/smp $)$

b. Untuk DS $\leq 0,6$ :

DT $=2+8,2078 \times$ DS $-(1-D S) \times 2$

Perhitungan tundaan lalu lintas simpang untuk periode siang :

$\mathrm{DT}=2+[(8,2078 \times 0,466)]-[(1-$ $0,466) \times 2]=4,766($ detik/smp $)$

c. Untuk DS $\leq 0.6$ :

$$
\text { DT }=2+8,2078 \times \text { DS }-(1-D S) \times 2
$$

Perhitungan tundaan lalu lintas simpang untuk periode sore :

DT $=2+[(8,2078 \times 0,340)]-[(1-0,340) \times$ 2] $=3,473$

2. Tundaan lalu lintas rata-rata untuk jalan utama (DTMA)

Tundaan lalu lintas rata-rata untuk jalan utama merupakan tundaan lalu lintas rata-rata untuk seluruh kendaraan yang masuk dari jalan utama.

a. Untuk DS $\leq 0,6$ :

$$
\mathrm{DT}=1,8+5,8234 \times \mathrm{DS}-(1-\mathrm{DS}) \times 1,8
$$

Perhitungan tundaan lalu lintas simpang untuk periode pagi :

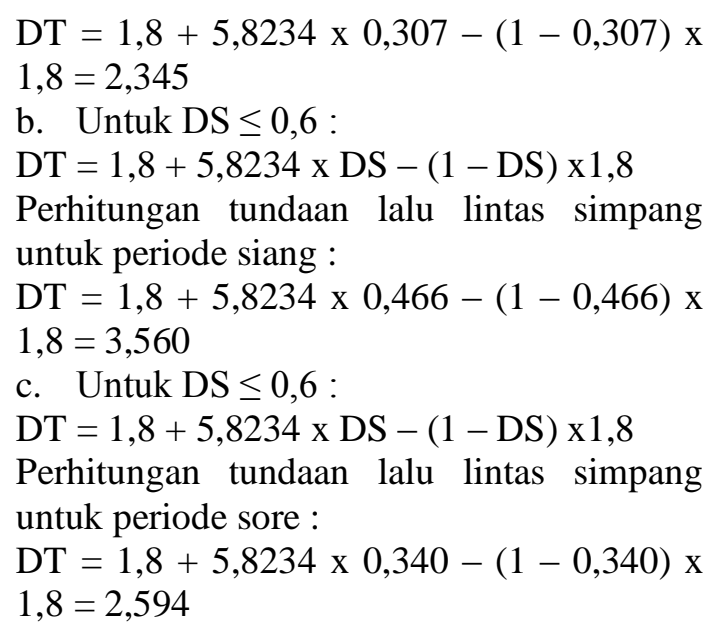

3. Tundaan lalu lintas rata-rata jalan minor (DTMI)

Tundaan lalu lintas rata-rata jalan minor ditentukan berdasarkan tundaan lalu lintas ratarata (DTi) dan tundaan lalu lintas rata-rata jalan utama (DTMA).

DTMI $=($ QTOT $\times$ DTI - QMA $\times$ DTMA $) / Q M I$

a. Perhitungan Tundaan lalu lintas rata-rata jalan minor untuk periode pagi :

$\mathrm{DTMI}=(1,018 \times 3,140-589,1 \times 2,345)$ / $214,8=8,462$

b. Perhitungan Tundaan lalu lintas rata-rata jalan minor untuk periode siang :

DTMI $=(1,490 \times 4,766-712,6 \times 3,560)$ / $386=11,828$

c. Perhitungan Tundaan lalu lintas rata-rata jalan minor untuk periode sore :

DTMI $=(1,134 \times 3,473-834,1 \times 2,594)$ / $312=5,694$

4. Tundaan geometrik simpang (DG)

Tundaan geometrik simpang adalah tundaan geometrik rata-rata seluruh kendaraan bermotor yang masuk di simpang.

$\mathrm{DG}=(1-\mathrm{DS}) \times(\mathrm{PT} \times 6+(1-\mathrm{PT}) \times 3)+\mathrm{DS} \times$ 4

a. Tundaan Geometrik simpang untuk periode pagi :

$\mathrm{DG}=(1-0,30) \times(0,62 \times 6+(1-0,62)$ x 3) $+0,30$ x $4=4,59$

b. Tundaan Geometrik simpang untuk periode siang :

$\mathrm{DG}=(1-0,46) \times(0,61 \times 6+(1-0,61)$ x 3) $+0,46$ x $4=4,43$

c. Tundaan Geometrik simpang untuk periode sore : 


$$
\mathrm{DG}=(1-0,34) \times(0,81 \times 6+(1-0,81)
$$$$
\text { x 3) }+0,34 \times 4=4,94
$$

5. Tundaan simpang (D)

Tundaan simpang dihitung menggunakan persamaan sebagai berikut :

$\mathrm{D}=\mathrm{DG}+\mathrm{DTi}$

a. Perhitungan Tundaan simpang untuk periode pagi :

$\mathrm{D}=4,59+3,140=7,733$ Detik/smp

b. Perhitungan Tundaan simpang untuk periode siang :

$\mathrm{D}=4,43+4,766=9,20$ Detik/smp

c. Perhitungan Tundaan simpang untuk periode sore :

$\mathrm{D}=4,94+3,473=8,422$ Detik/smp

\section{Peluang Antrian (QP\%)}

Batas nilai peluang antrian QP\% (\%) ditentukan dari hubungan empiris antara peluang antrian QP\% dan derajat kejenuhan DS. Peluang antrian dengan batas atas dan batas bawah dapat diperoleh dengan menggunakan persamaan 15 dan 16 sebagai berikut :

Batas atas : $\mathrm{QPa}=(47,71 \times \mathrm{DS})-\left(24,68 \times \mathrm{DS}^{2}\right)$ $+\left(56,47 \times \mathrm{DS}^{3}\right)$

Batas Bawah : $\mathrm{QPb}=(9,02 \times \mathrm{DS})+(20,66 \mathrm{x}$ $\left.\mathrm{DS}^{2}\right)+\left(10,49 \times \mathrm{DS}^{3}\right)$

a. Perhitungan Peluang Antrian untuk periode pagi :

$\mathrm{QPa}=(47,71 \times 0,307)-\left(24,68 \times 0,307^{2}\right)+$ $\left(56,47 \times 0,307^{3}\right)=13,98 \%$

$\mathrm{QPb}=(9,02 \times 0,307)+\left(20,66 \times 0,307^{2}\right)+$ $\left(10,49 \times 0,307^{3}\right)=1,12 \%$

b. Perhitungan Peluang Antrian untuk periode siang :

$\mathrm{QPa}=(47,71 \times 0,466)-\left(24,68 \times 0,466^{2}\right)+$ $\left(56,47 \times 0,466^{3}\right)=22,64 \%$

$\mathrm{QPb}=(9,02 \times 0,466)+\left(20,66 \times 0,466^{2}\right)+$ $\left(10,49 \times 0,466^{3}\right)=0,77 \%$

c. Perhitungan Peluang Antrian untuk periode sore :

$\mathrm{QPa}=(47,71 \times 0,340)-\left(24,68 \times 0,340^{2}\right)+$ $\left(56,47 \times 0,340^{3}\right)=15,60 \%$

$\mathrm{QPb}=(9,02 \times 0,340)+\left(20,66 \times 0,340^{2}\right)+$ $\left(10,49 \times 0,340^{3}\right)=1,09 \%$

\section{KESIMPULAN}

Dari hasil analisa kapasitas dan kinerja simpang tak bersinyal R.A. Kartini berdasarkan MKJI 1997, maka dapat ditarik kesimpulan bahwa kapasitas pada simpang tak bersinyal R.A
Kartini pada periode puncak pagi (07.00-08.00) sebesar 3,310.89 smp/jam, pada puncak siang (pukul 13.00-14.00) sebesar 3,190.65 smp/jam, dan pada puncak sore (pukul 17.00-18.00) kapasitas sebesar 3,333.62 smp/jam dan tingkat kinerja simpang tak bersinyal pada jalan R.A. Kartini pada saat jam sibuk dalam keadaan tidak jenuh karena mempunyai nilai derajat kejenuhan 0,3 -0,46 kurang dari yang di syaratkan MKJI 1997 yaitu 0,75, Untuk tundaan yang terjadi pada jam puncak pagi (pukul 07.00-08.00) yaitu sebesar 7,733 Detik/smp, pada puncak siang (pukul 13.00-14.00) yaitu sebesar 9,20 Detik/smp, dan pada puncak sore (pukul 17.0018.00) yaitu sebesar 8,422 Detik/smp, sedangkan Peluang antrian yang terjadi pada jam puncak pagi (pukul 07.00-08.00) yaitu sebesar 13,98\%, pada puncak siang (pukul 13.00-14.00) yaitu sebesar $22,64 \%$ dan pada puncak sore (pukul 17.00-18.00) yaitu sebesar $15,60 \%$

\section{DAFTAR PUSTAKA}

DPU. Direktorat Jendral Bina Marga (1997). Manual Kapasitas Jalan Indonesia, Departemen Pekerjaan Umum.

E-Journal uajy www. Retrieved Febuari 8, 2017, form http://ejournal.uajy.ac.id/3291/3/2TS1177 2.pdf.

Juniardi. (2006). Analisa Arus Lalu Lintas Di Simpang Tak Bersinyal (studi Kasus : Simpang Timoho dan Simpang Tunjung di Kota Yogyakarta). Tesis. Semarang : Universitas Diponegoro.

Khisty, C. J, Lall, B. K. (2003). Dasar-dasar Rekayasa Transportasi, Edisi ketiga Jilid satu, Erlangga, Jakarta.

Prasmesti, Y. I.. (2011). Studi Kinerja Simpang Tak Bersinyal Pasar nangka Atad Dasar Observasi

Rusmin, M. (2018, May 13). Analisis Kinerja Di Simpang Empat Tak Sebidang Kota Makassar Berbasis Mikrosimulasi. https://doi.org/10.17605/OSF.IO/C7HTN 